\title{
ABRvS 27 februari 2019 (terecht geen verklaring van geschiktheid wegens beperkt gezichtsveld), m.nt. prof. mr. A.C. Hendriks
}

Afdeling bestuursrechtspraak van de Raad van State 27 februari 2019 (mrs. C.H.M. van Altena, H.G. Lubberdink, E. Steendijk), zaaknr. 201709577/1/A2, ECLI:NL:RVS:2019:600, appellant/CBR

(...;red.)

\section{Procesverloop}

Bij besluit van 14 februari 2017 heeft het CBR geweigerd voor [appellant] een verklaring van geschiktheid af te geven voor het besturen van motorrijtuigen van de categorieën $\mathrm{C}$ en $\mathrm{CE}$.

Bij besluit van 13 juli 2017 heeft het CBR het door [appellant] daartegen gemaakte bezwaar ongegrond verklaard.

Bij uitspraak van 20 oktober 2017 heeft de voorzieningenrechter het door [appellant] daartegen ingestelde beroep ongegrond verklaard. Deze uitspraak is aangehecht.

Tegen deze uitspraak heeft [appellant] hoger beroep ingesteld.

Het CBR heeft een schriftelijke uiteenzetting gegeven.

De Afdeling heeft de zaak ter zitting behandeld op 31 juli 2018, waar [appellant], bijgestaan door mr. J. van Groningen, advocaat te Middelharnis, en het CBR, vertegenwoordigd door S.J.W. van de Vorstenbosch-Blom, zijn verschenen.

\section{Overwegingen}

\section{Inleiding}

1. [appellant] is een ervaren vrachtwagenchauffeur die zowel in het binnen- als buitenland heeft gere- den. Hij heeft op zeer jonge leeftijd een ongeluk gehad en daarbij een schedelbasisfractuur opgelopen. Als gevolg van een operatie is zijn gezichtsveld beperkt.

In de periode voorafgaande aan zijn aanvraag voor vernieuwing van zijn rijbewijs is het CBR aan deze beperking voorbijgegaan. Volgens het CBR was het hiervan niet op de hoogte omdat dit op eerdere aanvragen van [appellant] uit 2007 niet was vermeld.

2. Het CBR heeft geweigerd voor [appellant] een verklaring van geschiktheid af te geven voor het besturen van motorrijtuigen van de categorieën $C$ en CE (vrachtwagen) omdat [appellant] een beperkt gezichtsveld heeft. Hierbij heeft het CBR verwezen naar paragraaf 3.3 , onder $b$, van de bijlage bij de Regeling eisen geschiktheid 2000 (hierna: de regeling). In deze paragraaf staat dat het binoculaire horizontale gezichtsveld van [appellant] minimaal 160 graden moet zijn om de gevraagde verklaring van geschiktheid te krijgen. Omdat [appellant] hieraan niet voldoet, kon het CBR niet anders dan de aanvraag afwijzen. Daarom heeft het CBR het positieve advies van oogarts M.A. Sawas (hierna: de oogarts) van 11 januari 2017 niet gevolgd.

\section{Oordeel van de voorzieningenrechter}

3. De voorzieningenrechter heeft geoordeeld dat paragraaf 3.3, onder b, van de bijlage bij de regeling niet in strijd is met het evenredigheidsbeginsel. Ook biedt deze paragraaf volgens de voorzieningenrechter geen ruimte voor afwijking. De dwingendrechtelijke eis van 160 graden gezichtsveld van deze paragraaf is overgenomen uit punt 6.4 van Bijlage III van Richtlijn 2006/126/EG van het Europees Parlement en de Raad van 20 december 2006 betreffende 
het rijbewijs (PB 2006, L 403/18, hierna: de derde rijbewijsrichtlijn). Punt 6.4 ziet op minimumnormen inzake lichamelijke en geestelijke geschiktheid voor het besturen van een gemotoriseerd voertuig en hierop is volgens de voorzieningenrechter geen uitzondering mogelijk. Het CBR heeft het advies van de oogarts dan ook terecht niet overgenomen, aldus de voorzieningenrechter.

\section{Hoger beroep}

4. [appellant] kan zich met dit oordeel van de voorzieningenrechter niet verenigen.

Volgens [appellant] bevat zowel punt 6.4 van Bijlage III van de derde rijbewijsrichtlijn als paragraaf 3.3 van de bijlage bij de regeling geen strikte minimumnorm. Zo worden ingevolge punt 4 van Bijlage III bestuurders bij elke verlenging van het rijbewijs getest volgens het nationale systeem van de lidstaat van normaal verblijf. In dit verband verwijst [appellant] naar paragraaf 3.5 (rijtest) en 3.6 (nader oogheelkundig onderzoek) van de bijlage bij de regeling. Bovendien mogen rijbewijzen ingevolge punt 6.4 van Bijlage III van de derde rijbewijsrichtlijn slechts niet worden afgegeven of verlengd indien de aanvrager lijdt aan verminderde contrastgevoeligheid of diplopie. De norm voor het horizontale gezichtsveld in deze bijlage bevat niet een soortgelijke weigeringsgrond en is dus geen strikte norm, aldus [appellant]. Volgens [appellant] staat de derde rijbewijsrichtlijn dan ook niet aan buitentoepassingverklaring van paragraaf 3.3, onder $b$, van de bijlage bij de regeling in de weg. In dit verband verwijst hij naar de uitspraak van de rechtbank Rotterdam van 28 oktober 2016 (ECLI:NL:RBROT: 2016:8212).

[appellant] betoogt voorts dat de voorzieningenrechter ten onrechte niet heeft onderkend dat het CBR het positieve advies van de bedrijfsarts en de oogarts had moeten overnemen en dus de gevraagde verklaring van geschiktheid voor vernieuwing van het rijbewijs had moeten afgeven. Hierbij verwijst [appellant] naar de uitspraak van de Afdeling van 17 december 2014 (ECLI:NL:RVS: 2014:4563). Ook gaat het bij [appellant] slechts om een beperkt gezichtsveld aan de linkerzijde, opgetre- den in zijn eerste levensjaar, en was het CBR hiervan al eerder op de hoogte. Daarbij komt dat [appellant] gewend is geraakt is aan zijn beperkte gezichtsveld en de vrachtwagencombinatie jarenlang over een groot aantal kilometers schadevrij heeft bestuurd. De verkeersveiligheid is volgens [appellant] dan ook niet in geding geweest. Doordat hem geen verklaring van geschiktheid is verstrekt kan [appellant] zijn beroep als vrachtwagenchauffeur niet meer uitoefenen hetgeen volgens hem betekent dat het CBR in strijd met het evenredigheidsbeginsel heeft gehandeld.

Gelet hierop had het CBR paragraaf 3.3, onder b, van de bijlage bij de regeling buiten toepassing moeten laten, aldus [appellant].

5. Het wettelijk kader is opgenomen in de bijlage, die deel uitmaakt van deze uitspraak.

6. [appellant] valt als bestuurder van een vrachtwagen in groep 2 als bedoeld in punt 1.2 van Bijlage III van de derde rijbewijsrichtlijn en artikel 1, aanhef en onder $b$, van de regeling.

Niet in geschil is dat het binoculaire horizontale gezichtsveld van [appellant] minder dan 160 graden is en dat [appellant] niet voldoet aan de in paragraaf 3.3, onder b, van de bijlage bij de regeling neergelegde norm.

7. De derde rijbewijsrichtlijn is op 19 januari 2007 in werking getreden. Blijkens de considerans van deze richtlijn zijn bij de voorschriften het subsidiariteitsbeginsel en het evenredigheidsbeginsel in acht genomen. Ook staat in de considerans dat de voorschriften betreffende het rijbewijs bijdragen tot de veiligheid van het wegverkeer. Om aan de eisen inzake de veiligheid van het wegverkeer te voldoen dienen minimumvoorwaarden te worden vastgesteld voor de afgifte van het rijbewijs. Ook moet een verdere harmonisatie van de normen inzake de door de bestuurders af te leggen rijexamens en inzake de afgifte van rijbewijzen worden uitgevoerd. Daartoe moeten de minimumnormen inzake lichamelijke en geestelijke geschiktheid voor het besturen van die voertuigen opnieuw worden omschreven. 
Punt 6.4 van Bijlage III is sinds 25 augustus 2009 in de richtlijn opgenomen (Richtlijn 2009/113/EG van de Commissie van 25 augustus 2009 tot wijziging van Richtlijn 2006/126/EG van het Europees Parlement en de Raad betreffende het rijbewijs; PB 2009, L 223/31). Hieraan ligt nader onderzoek naar gezichtsvermogen ten grondslag. De bijlage bij de regeling is daarom, overeenkomstig de richtlijn, aangepast. Sinds 22 februari 2010 is in paragraaf 3.3, onder b, van de bijlage de 160 graden norm opgenomen. In de toelichting hierbij (Staatscourant 2010, 2588) staat dat de Commissie een aantal minimumnormen op het gebied van het gezichtsvermogen aan de huidige inzichten van de medische wetenschap heeft aangepast. Als basis hiervoor dient een drietal deskundigenrapporten uit 2005, die op verzoek van de Commissie zijn uitgebracht.

8. Punt 6.4 van Bijlage III van de derde rijbewijsrichtlijn bevat een minimumnorm met betrekking tot het vereiste gezichtsveld. In punt 6 van de bijlage is voorzien in een uitzondering hierop die geldt voor groep 1. Voor de door [appellant] gevraagde verlenging van zijn rijbewijs $C$ en $C E$, die valt onder groep 2, geldt deze uitzondering dus niet. Paragraaf 3.3 van de bijlage bij de regeling is hiermee in overeenstemming. De voorzieningenrechter heeft daarom terecht geen grond gezien voor het buiten toepassing laten van deze bepaling. Het betoog van [appellant] dat de regelgeving met betrekking tot rijbewijzen behorend tot groep 2 ruimte biedt voor een uitzondering op de eis over het gezichtsveld kan gelet op het voorgaande evenmin worden gevolgd. Ook de door [appellant] genoemde uitspraak van de rechtbank Rotterdam van 28 oktober 2016 laat dit oordeel onverlet. Weliswaar heeft de rechtbank in deze uitspraak aanleiding gezien vanwege uitzonderlijke omstandigheden de regeling buiten toepassing te laten, maar deze uitspraak is bij uitspraak van de Afdeling van 1 november 2017 (ECLI:NL:RVS:2017:2932) vernietigd.

De stelling van [appellant] dat rijbewijzen slechts niet mogen worden afgegeven of verlengd indien de aanvrager lijdt aan verminderde contrastgevoeligheid of diplopie berust op een onjuiste lezing van punt 6.4 van de Bijlage III van de derde rijbewijsrichtlijn. De desbetreffende zin heeft geen betrekking op aanvragers met een gezichtsveld van minder dan 160 graden.

$\mathrm{Nu}$ de beperking van het gezichtsveld van [appellant] tot gevolg heeft dat buiten twijfel is dat hij niet voldoet aan de vereisten van paragraaf 3.3 van de bijlage bij de regeling wordt aan toepassing van paragraaf 3.5 en 3.6 niet toegekomen.

9. Zoals onder 7. is overwogen is de veiligheid van het wegverkeer een uitgangspunt van de derde rijbewijsrichtlijn. Wat betreft het gezichtsvermogen zijn bij de eerder genoemde Richtlijn 2009/113/EG een aantal minimumnormen aangepast aan de huidige inzichten van de medische wetenschap. Daarmee is de strikte 160 graden norm onderbouwd en toegelicht. De motieven die zijn gelegen in verband met de verkeersveiligheid aan de actuele medische wetenschap angepaste minimumnormen verklaren dus de in de regel opgenomen strengheid in de zin dat hierin geen uitzondering is opgenomen.

Hetgeen [appellant] betoogt over de Europese beginselen van subsidiariteit en evenredigheid is door de voorzieningenrechter met juistheid verworpen in overweging 8.1. van de aangevallen uitspraak. Uit hetgeen de Afdeling onder 8 heeft overwogen volgt dat paragraaf 3.3 van de bijlage bij de regeling een juiste implementatie is van punt 6.4 van Bijlage III van de derde rijbewijsrichtlijn en dat hierin een minimumnorm is vervat waarop geen uitzondering mogelijk is.

Het is niet aan een nationale rechter te oordelen over de ongeldigheid van een bepaling uit een Europese richtlijn. Aangezien uit het voorgaande volgt dat bij de Afdeling geen twijfel bestaat over de geldigheid van punt 6.4. van Bijlage III van de derde rijbewijsrichtlijn, ziet de Afdeling, gelet op het arrest van het Hof van Justitie van 22 oktober 1987 in de zaak Foto Frost (arrest van 22 oktober 1987, FotoFrost/Hauptzollamt Lübeck-Ost, ECLI:EU:C: 1987:452, punten 14-15) geen aanleiding tot het stellen van prejudiciële vragen over de geldigheid van punt 6.4.

Het betoog faalt. 
10. Volgens het geneeskundig verslag van bedrijfsarts J.H. Zwiers van 25 augustus 2016 is het gezichtsveld van [appellant] beperkt. Zwiers komt echter wel tot het advies: 'geschikt'.

In het eerdergenoemde advies van de oogarts van 11 januari 2017 staat dat er aanwijzingen zijn voor defecten in het gezichtsveld, [appellant] al 10 jaar een groot rijbewijs heeft, in 1989 een ongeluk heeft gehad en is geopereerd. Het advies luidt: voldoet aan de normen van de regeling voor groep 2 (vrachtauto en bus) voor onbeperkte termijn ( 5 jaar).

Uit overwegingen 8. en 9. volgt dat het het CBR niet vrijstaat af te wijken van de 160 graden norm voor het horizontale gezichtsveld. Dat, zoals [appellant] betoogt, het CBR is geadviseerd ondanks het gezichtsvelddefect in strijd met deze norm een verklaring van geschiktheid af te geven maakt niet dat het CBR in strijd met artikel 103, eerste lid, van het Reglement rijbewijzen de gevraagde verklaring van geschiktheid in het rijbewijzenregister dient in te schrijven. Hierbij verwijst de Afdeling naar haar bestendige jurisprudentie op dit vlak (zie bijvoorbeeld de uitspraak van de Afdeling van 28 november 2012, ECLI:NL:RVS:2012:BY4419). De door [appellant] in dit verband genoemde uitspraak van de Afdeling van 17 december 2014 (ECLI:NL:RVS: 2014:4563) ziet op een andere situatie. In die zaak was de vraag aan de orde of het gezichtsvermogen al dan niet voldoende was en het CBR de juiste medische beoordeling aan het besluit tot afwijzing van de gevraagde verklaring van geschiktheid ten grondslag had gelegd.

Omdat de regeling geen ruimte laat om per geval rekening te houden met individuele belangen, had het CBR ook wat betreft de door [appellant] genoemde belangen een vrachtwagen te blijven rijden geen mogelijkheid hem geschikt te verklaren. Dat hij voorheen onder gelijke omstandigheden wel heeft beschikt over een rijbewijs en schadevrij heeft gereden maakt evenmin dat het CBR in strijd met het hiervoor genoemde artikel van het Reglement rijbewijzen de gevraagde verklaring van geschiktheid dient in te schrijven. Zie voor vaste jurisprudentie op dit punt bijvoorbeeld de uitspraak van de
Afdeling van 14 april 2010 (ECLI:NL:RVS: 2010:BM1043).

Het betoog faalt.

11. Over het betoog van [appellant] op de zitting bij de Afdeling dat hij geschikt wil worden verklaard voor het rijden van een vrachtwagen enkel in Nederland, merkt de Afdeling op dat dit in deze procedure niet aan de orde kan komen en dat [appellant] een aanvraag met deze strekking bij het CBR kan indienen.

12. Het hoger beroep is ongegrond. De aangevallen uitspraak dient te worden bevestigd.

13. Voor een proceskostenveroordeling bestaat geen aanleiding.

\section{Beslissing}

De Afdeling bestuursrechtspraak van de Raad van State:

bevestigt de aangevallen uitspraak.

\section{Noot}

1. In de bovenstaande zaak stelt appellant zich op het standpunt dat het Centraal Bureau Rijvaardigheidsbewijzen (CBR) ten onrechte heeft geweigerd voor hem een verklaring van geschiktheid af te geven voor het besturen van motorrijtuigen van de categorieën C en CE (vrachtwagen). Het CBR zou hiertoe zijn overgegaan omdat appellant, een ervaren vrachtwagenchauffeur, een beperkt gezichtsveld heeft als gevolg van een ongeluk met een schedelbasisfractuur als gevolg. De weigering van de verklaring van geschiktheid heeft tot gevolg dat appellant zijn werk niet meer kan uitoefenen. Ondanks zijn goed onderbouwde bezwaren verklaart de Afdeling bestuursrechtspraak van de Raad van State (Afdeling) de gronden van hoger beroep ongegrond. Met het CBR en de voorzieningenrechter is de Afdeling van oordeel dat er voor appellant geen uitzondering kan worden gemaakt. Het (bestuurs)recht voorziet daar niet in. Dit vraagt om een toelichting. 
2. Volledigheidshalve eerst het volgende. Het CBR is een zelfstandig bestuursorgaan. Zijn primaire taak bestaat eruit om de rijvaardigheid (theorie- en rijexamen) en de lichamelijke en geestelijke geschiktheid (rijgeschiktheid) van personen te toetsen die een rijbewijs hebben of willen krijgen. Beslissingen die het CBR neemt zijn daarom voor bezwaar en beroep vatbaar. Dit verklaart waarom het geschil tussen appellant en het CBR in de bovenstaande zaak uiteindelijk aan de Afdeling is voorgelegd.

3. Appellant in de bovenstaande zaak meende dat het CBR in zijn geval ten onrechte was overgegaan tot het niet afgeven van een verklaring van geschiktheid op basis van zijn Gezondheidsverklaring (voorheen: Eigen verklaring). Appellant bestrijdt dat het CBR dit besluit kon nemen op basis van paragraaf 3.3, onder b, van de bijlage bij de Regeling eisen geschiktheid 2000. Zijns inziens bevat deze bepaling, inzake het binoculaire horizontale gezichtsveld, geen strikte norm. Appellant wijst voorts op het positieve advies van zijn oogarts, dat het CBR volgens hem had moeten overnemen. Appellant is in de derde plaats de mening toegedaan dat hij geen gevaar vormt voor de verkeersveiligheid - en stemt in met een verklaring waarmee hij alleen in Nederland mag rijden. Hij is namelijk gewend aan zijn (beperkte) gezichtsvermogen en heeft jaren lang schadevrij gereden. Nu dreigt hij het recht te verliezen om motorrijtuigen van de categorieën $C$ en $C E$ te besturen, en aldus zijn baan te verliezen.

4. Het CBR had de gronden van beroep afgewezen. De voorzieningenrechter kwam eveneens tot de conclusie dat appellants gronden van beroep ongegrond waren. Met het CBR was de voorzieningenrechter het oordeel toegedaan dat paragraaf 3.3, onder b, van de bijlage bij de Regeling eisen geschiktheid 2000 geen ruimte laat voor afwijking. De voorzieningenrechter was voorts van mening dat deze bepaling niet strijdig is met het evenredigheidsbeginsel, zodat appellant niet disproportioneel in zijn belangen wordt getroffen bij een eventueel verlies van zijn baan.
5. Anders dan appellant had gehoopt, verklaart ook de Afdeling zijn gronden van hoger beroep ongegrond. $\mathrm{Na}$ bestudering van paragraaf 3.3 , onder $\mathrm{b}$, van de bijlage bij de Regeling eisen geschiktheid 2000 komt ook de Afdeling tot de conclusie dat deze bepaling een minimumnorm bevat. Het CBR mag daarvan dus niet afwijken. Een afwijking is evenmin toegestaan als een verzoek om een verklaring van rijgeschiktheid tezamen met medische verklaringen wordt ingediend waarin de rijgeschiktheid van een aanvrager door artsen wordt bevestigd. Zoals gezegd, het CBR mag niet afwijken van een dwingendrechtelijke norm (zie eerder ABRvS 28 december 2011, ECLI:NL:RVS:2011:BU9476 en ABRvS 11 maart 2015, ECLI:NL:RVS:2015:748).

6. Dat de Afdeling evenmin instemt met de stelling van appellant dat hij wel rijgeschikt is en alleen in Nederland wil rijden, spreekt voor zich. Volgens de Afdeling kan zo'n standpunt niet in de procedure worden betrokken, waarmee de Afdeling deze grond van hoger beroep eveneens ongegrond verklaart.

7. Het CBR heeft in de bovenstaande zaak het verzoek van appellant om een verklaring van rijgeschiktheid terecht afgewezen. Het toetsingskader is nu eenmaal dwingendrechtelijk. Dit heeft alles te maken met het belang dat we in onze samenleving toekennen aan de verkeersveiligheid, een belang dat lidstaten van de EU ook volgens Europese regels verplicht zijn te waarborgen. Ondanks de omstandigheid dat bij de wegenverkeerswetgeving getracht is een balans te vinden tussen dit publieke belang en het individuele belang van de aanvrager van een rijbewijs, voorziet het bestuursrecht niet in de mogelijkheid voor het individu om een beroep te doen op de civielrechtelijke redelijkheid en billijkheid.

Prof. mr. A.C. Hendriks,

hoogleraar Gezondheidsrecht aan de Universiteit Leiden (Faculteit der Rechtsgeleerdheid). 